\title{
Design of Thames Barrier
}

SIR-F. Kenneth Hare and Kenneth Mellanby (Nature 334, 646; 1988), adduced arguments for "jumping the greenhouse gun' which are fortuitously linked by a recent study' at the Institute of Hydrology. The divergent responses to the greenhouse effect of Hare the scientist and Hare the government adviser are a current manifestation of an old problem; one which is neatly illustrated with the question of the Thames Barrier raised by Mellanby.

The same distinction existed between (a) the design criteria for the estuary defences seaward of the barrier and (b) the design standard adopted for the barrier dimensions and landward defences (the barrier is one element in an integrated scheme for protecting the entire tideway). Case (a) was scientifically based on the 1,000 -year return period level in the year 2030. By contrast, case (b) was arrived at by simulating the consequences of versions of the February 1953 event, the most severe of which consisted of adding $6 \mathrm{ft}(1.83 \mathrm{~m})$ to the 1953 high water. Herein lies the source of the dichotomy; in the seaward case (a), the technology and data existed for a formal solution of the design problem. For the barrier itself and upriver, the complexity of the situation - joint fluvial influences and barrier operation - surpassed available statistical design techniques: designers therefore proceeded on the basis of a suitably severe 'scenario', the alternative of delaying construction until design technology 'caught up' rightly being unthinkable.

Mellanby feels misled about whether or not the greenhouse effect was considered in the barrier design. The study by the (then) Institute of Coastal Oceanography and Tides identified isostatic adjustment and man-made estuary geometry changes as the primary causes of a positive trend, but contemporary papers reveal that the possibility of eustatic influences was considered. Thus the short answer would appear to be that the greenhouse effect was not explicitly considered (few were so farsighted in the 1960s) but that the aggregate effect of all influences was. Design levels for the seaward reaches were projected forward to the year 2030 at annual increases of $3.8 \mathrm{~mm}$ at Southend increasing upriver towards $8.5 \mathrm{~mm}$ at Tower Pier.

The original barrier design calculations have been reviewed as part of a recent study of Thames estuary defences by this institute and Sir William Halcrow and Partners. Our updating of the high-water data and reanalysis reveals a strong downturn after 1970 parelleling the southern North Sea mean sea level trend ${ }^{2}$, and little evidence for a differential trend in the upper estuary. Seasonal and other periodicities dominate secular trend in control- ling the parameters of the distribution of high water. Upstream of the barrier, a joint probability analysis of the fluvial and tidal components (not possible at the time the barrier was designed) has highlighted the importance of the timely closure of the barrier against an uncertain surge forecast.

I am engaged in climate change impact analysis in the water resources field and my view coincides with Hare's in that as a scientist one does admit the uncertainties and unaccounted feedback mechanisms that may aggravate or ameliorate the effect. However, as an adviser, one has to be less dispassionate and attach greater weight to outcomes with the more severe consequences. In practical impact analysis in hydrology ${ }^{3}$, this means adopting some 'scenario' for change, this term generally being preferred to 'forecast' because it conveys better the 'what-if' feeling of an arbitrary although realistic and internally consistent planning tool. Climate change scenarios are based upon general circulation models, on extrapolation from contrasts between historic warm and cool periods, and by adopting analogue regions - for example, that future British river flows will resemble those current in southwest France. This is not established fact, but a working hypothesis which awaits resolution by better models (or possibly by the evolution of events).

\section{Hydrological Extremes and Climate}

Max Beran

Change Group,

Institute of Hydrology,

\section{Wallingford, $O X 108 B B, U K$}

1. Beran. M. A.. Jones, D. A.. Harpin, R. \& Smith, A. L. P Proc. Sth IAHR International Symposium on Stochastic Hydraulics. Birmingham 2-4 August 1988.

2. Woodworth, P. L. Mar. Geodesy 11, 57-87 (1981).

Beran, M. A. Proc. Int. Conf. on Health and Environmental Effects of Ozone Modification and Climate Change. Washington, 16-20 June 1986. UNEP/EPA.

\section{Leukaemia in UK}

SIR-I was interested to see J.H. Fremlin's letter (Nature 334, 8; 1988) as I studied a cluster of leukaemia cases in Kingston, Surrey, during the $1960 \mathrm{~s}$ in which the influence of radiation was not a factor ${ }^{\mathrm{l}}$. These phenomena were noted in the literature long before the advent of nuclear power stations (one of the earliest published in the United Kingdom refers to leukaemia in Cornwall in the 1940s).

Leukaemia and lymphoma in humans (as in animals) are undoubtedly associated with viruses that are probably latent and vertically or horizontally transmitted.

The emergence of leukaemia and lymphomas in transplant and immunoincompetent patients has shown us that induction can be caused by immunosuppressive events, of which radiation is only one. A much more common cause might be found in epidemics of virus infection (for example influenza) which can be immunsuppressive on a worldwide scale. It is important therefore to study these clusters, in relation not only to radiation but to the use of drugs which are cytotoxic or interfere with immune function and to the effects of local epidemics of infectious disease which may have caused immunosuppression.

There is a clear analogy with other severe illnesses (for example meningococcal meningitis) which may be precipitated in a cluster of otherwise healthy carriers by a previous virus infection ${ }^{2}$.

E.G. Dowsett

Microbiology Department,

Southend Hospital,

Prittlewell Chase,

Westcliff-on-Sea, Essex SSO ORY, UK

Dowsett, E.G. Br. J. Cancer 20, 16-31 (1966)

Pether. J.V.S. et al. Epidem. Infect. 101, 21-42(1988)

\section{Philosophy fails}

SIR-E. Zuckerkandl's welcome letter (Nature 334, 376; 1988) exemplifies the failure of modern philosophy to provide terminology with which to define and discuss the philosophical position he describes. The single word 'dualism' suffers from the fact that one of its several meanings is theological.

This problem was well recognized in the book Science versus Materialism (Methuen, 1940). The author, R.O. Kapp, professor of electrical engineering at University College London (with assistance from his colleague the professor of Greek), coined the term 'diathetics'. 'Diathesis' means the act of disposing to a specification or the being so disposed; a 'diatheme' is the result of a diathesis. These terms were included in The 'Mental' and the 'Physical' by $\mathrm{H}$. Feigl (University of Minnesota Press, 1958), but have not gained currency.

On Kapp's view, the primary concern of your journal is non-diathetic reality another expression for matter. But he would claim that in all that large fraction of your contents dealing with the structure and behaviour of living organisms you are also covering diathetics. In Zuckerkandl's words, such a view is 'naturalistic' but not in the least 'supernatural'. You would do a great service to the debate by adopting Kapp's terms almost 50 years after he proposed them.

\section{Vicarage Road,}

D.H. TOMPSETT

Henley-on-Thames,

Oxfordshire RG9 $1 \mathrm{HW}, U K$

Letters submitted for Correspondence should be typed, double-spaced, on one side of the paper only. 